\title{
Dentoskeletal and soft tissue changes in class II subdivision treatment with asymmetric extraction protocols
}

\author{
Guilherme Janson ${ }^{1 *}$, Eduardo Beaton Lenza ${ }^{1}$, Rodolfo Francisco ${ }^{1}$, Aron Aliaga-Del Castillo ${ }^{1} \mathbb{B}$, Daniela Garib ${ }^{1}$ \\ and Marcos Augusto Lenza²
}

\begin{abstract}
Background: This study cephalometrically compared the dentoskeletal and soft tissue changes consequent to one and three-premolar extraction protocols of class II subdivision malocclusion treatment.

Methods: A sample of 126 lateral cephalometric radiographs from 63 patients was selected and divided into two groups. Group 1 consisted of 31 type 1 class II subdivision malocclusion patients treated with asymmetric extractions of two maxillary premolars and one mandibular premolar on the class I side, with an initial mean age of 13.58 years. Group 2 consisted of 32 type 2 class II subdivision malocclusion patients treated with asymmetric extraction of one maxillary first premolar on the class II side, with an initial mean age of 13.98 years. $t$ test was used for intergroup comparison at the pre- and posttreatment stages and to compare the treatment changes.

Results: Group 1 had greater maxillomandibular sagittal discrepancy reduction and greater maxillary first molar extrusion. Group 2 had mandibular incisor labial inclination and protrusion, and group 1 had mandibular incisor lingual inclination and retraction. Maxillary molar asymmetry increased in group 2, while mandibular molar asymmetry increased in group 1.
\end{abstract}

Conclusions: The treatment changes produced by these two class II subdivision protocols are different to adequately satisfy the different needs for types 1 and 2 class II subdivision malocclusions.

Keywords: Class II subdivision, Premolar extractions, Asymmetric extractions, Cephalometrics

\section{Background}

Two main types of class II subdivision malocclusions have been identified. Type 1 class II subdivision malocclusions are characterized by distal positioning of the mandibular first molar on the class II side, coincidence of the maxillary dental midline with the midfacial plane and deviation of the mandibular dental midline to the class II side, in a frontal clinical view [1-5]. Type 2 class II subdivision malocclusions are characterized by mesial positioning of the maxillary first molar on the class II side, deviation of the maxillary dental midline to the class I side and coincidence of the mandibular dental midline with the midfacial plane $[4,5]$. There is also a

\footnotetext{
* Correspondence: jansong@travelnet.com.br

${ }^{1}$ Department of Orthodontics, Bauru Dental School, University of São Paulo,

Alameda Octávio Pinheiro Brisolla 9-75, Bauru 17012-901, Brazil

Full list of author information is available at the end of the article
}

third type, with combined characteristics of the first two types. Consequently, in this type, the maxillary midline is deviated to one side and the mandibular midline is deviated to the other $[4,5]$.

One of the treatment options for type 1 class II subdivision malocclusions consists in extractions of two maxillary premolars and one mandibular premolar on the class I side, as long as the facial profile and/or the amount of crowding allow extractions to be performed [1, 6-12]. For type 2 class II subdivision malocclusions, a treatment option may consist in extracting one maxillary premolar on the class II side $[1,4,6,8,13,14]$. Therefore, it is speculated that the amount of dentoskeletal and soft tissue retraction is larger for the first treatment option. However, this has not been investigated.

When faced with the third type of class II subdivision malocclusion, the orthodontist may have to choose 
whether to treat it is as a type 1 or type 2 class II subdivision malocclusion, with the mentioned protocols. Therefore, knowing the differences in the dentoskeletal and soft tissue changes provided by both treatment protocols, it will be possible to select the best protocol to address the characteristics of the specific malocclusion.

Therefore, the objective of this work is to test the following null hypothesis: dentoskeletal and soft tissue changes are similar between type 1 class II subdivision malocclusions treated with two maxillary and one mandibular premolar extractions to type 2 class II subdivision malocclusions treated with one maxillary premolar extraction.

\section{Methods}

This study was approved by the Ethics Committee of Bauru Dental School, University of São Paulo, Brazil. Sample size calculation, considering an $80 \%$ of test power at a significance level of $5 \%$, with a minimum mean difference to be detected of $0.85 \mathrm{~mm}$ in $1-\mathrm{NB}$, with a standard deviation of $1.19 \mathrm{~mm}$, revealed that 31 individuals in each of the two groups were the minimum amount necessary [9].

Therefore, 63 patients, of White Mediterranean ancestry, initially presenting with class II subdivision malocclusions were retrospectively selected from the files of the Orthodontic Department at Bauru Dental School, University of São Paulo, Brazil. These patients were treated between 1998 and 2012 and were divided into two groups, according to their treatment approach. Group 1 consisted of 31 patients with type 1 class II subdivision malocclusions, with initial and final mean ages of 13.58 and 16.83 years, respectively, and a mean treatment time of 3.25 years, treated with asymmetric extractions of two maxillary premolars and one mandibular premolar on the class I side. Group 2 consisted of 32 patients with type 2 class II subdivision malocclusions, with initial and final mean ages of 13.98 and 16.90 years, respectively, and a mean treatment time of 2.92 years, treated with asymmetric extraction of one maxillary premolar on the class II side (Figs. 1 and 2).

The primary selection criterion was that patients presented a full class II molar relationship on one side and class I molar relationship on the opposite side. Additional selection criteria were: presence of all maxillary and mandibular permanent teeth up to the first molars, absence of supernumerary and impacted teeth, agenesis and anomalies of size and/or shape of the teeth, no facial trauma or medical history that could have altered the normal growth of their apical bases, no previous orthodontic treatment, initial and final records in satisfactory conditions, and good occlusal outcomes [2, 4].

All patients were treated with conventional edgewise or preadjusted fixed appliances (Roth prescription), both with $0.022 \times 0.028$ in. metalic brackets, by graduate students supervised by the same clinical instructor (GJ). Fixed or removable functional appliances were not used. The usual wire sequence began with 0.014 in. Niti archwires, followed by $0.016 \mathrm{in}$. Niti and 0.018, 0.020, and finally $0.018 \times 0.025$ in. stainless steel archwires. Thereafter, enmasse retraction of the anterior teeth was performed. Anchorage reinforcement with cervical extraoral headgear and lip bumpers (at the gingival margin of incisors) $[9,15]$ were used in all patients to maintain the original posterior teeth anteroposterior relationships. Class II elastics were used $18 \mathrm{~h}$ a day, for minor

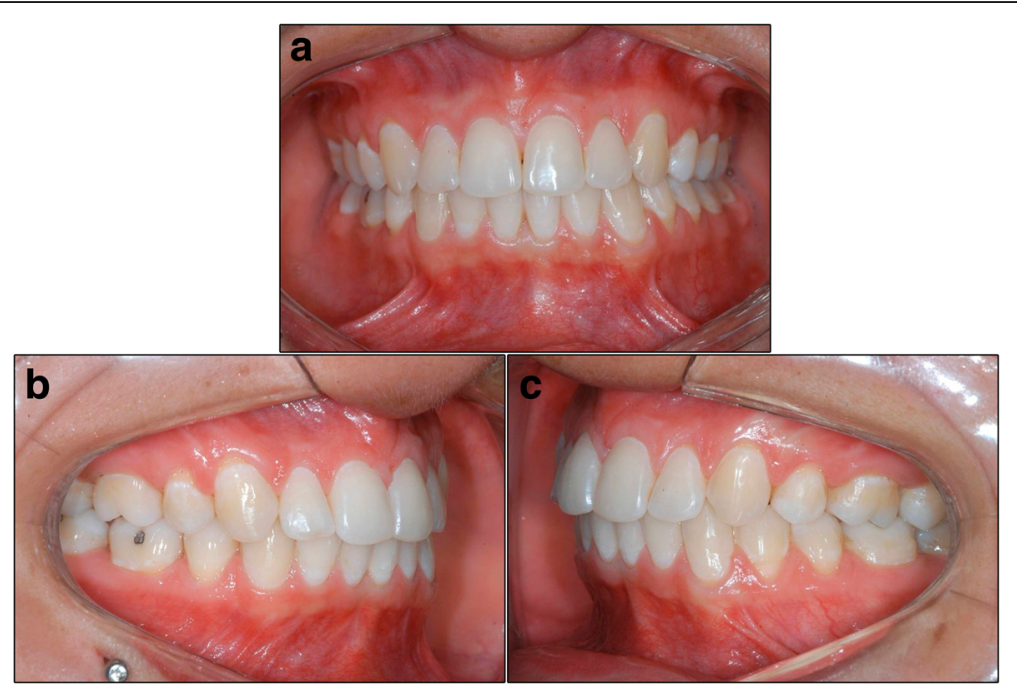

Fig. 1 Group 1 patient - front (a), right side (b), left side (c) 


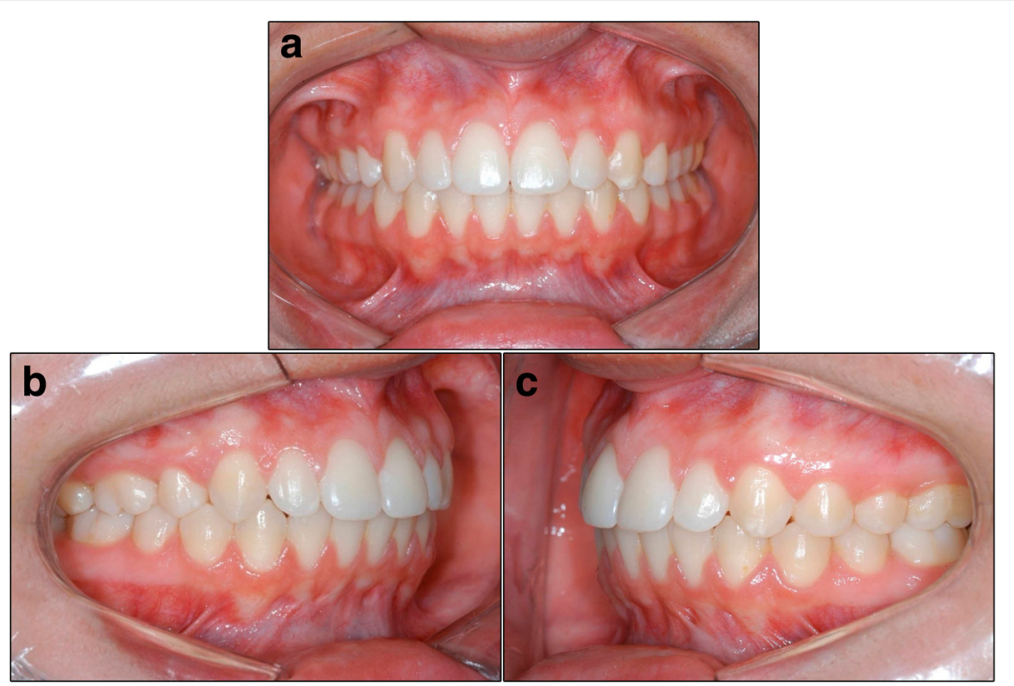

Fig. 2 Group 2 patient - front (a), right side (b), left side (c)

anteroposterior adjustment in the final stages, with $0.018 \times 0.025$ in. stainless steel archwires. Deep bites were usually corrected with accentuated and reversed curve of Spee on the archwires. As retention, the patients in both groups used Hawley plates on the maxillary arch and canine-to-canine bonded retainers.
The pretreatment and posttreatment lateral cephalograms were obtained from each patient and scanned to allow the acquisition of images by Dolphin ${ }^{\circ}$ Imaging 11.5 (Patterson Dental Supply, Inc., Chatsworth, CA). The magnification factors of the radiographic images that varied from 6 to $9.8 \%$ were corrected by

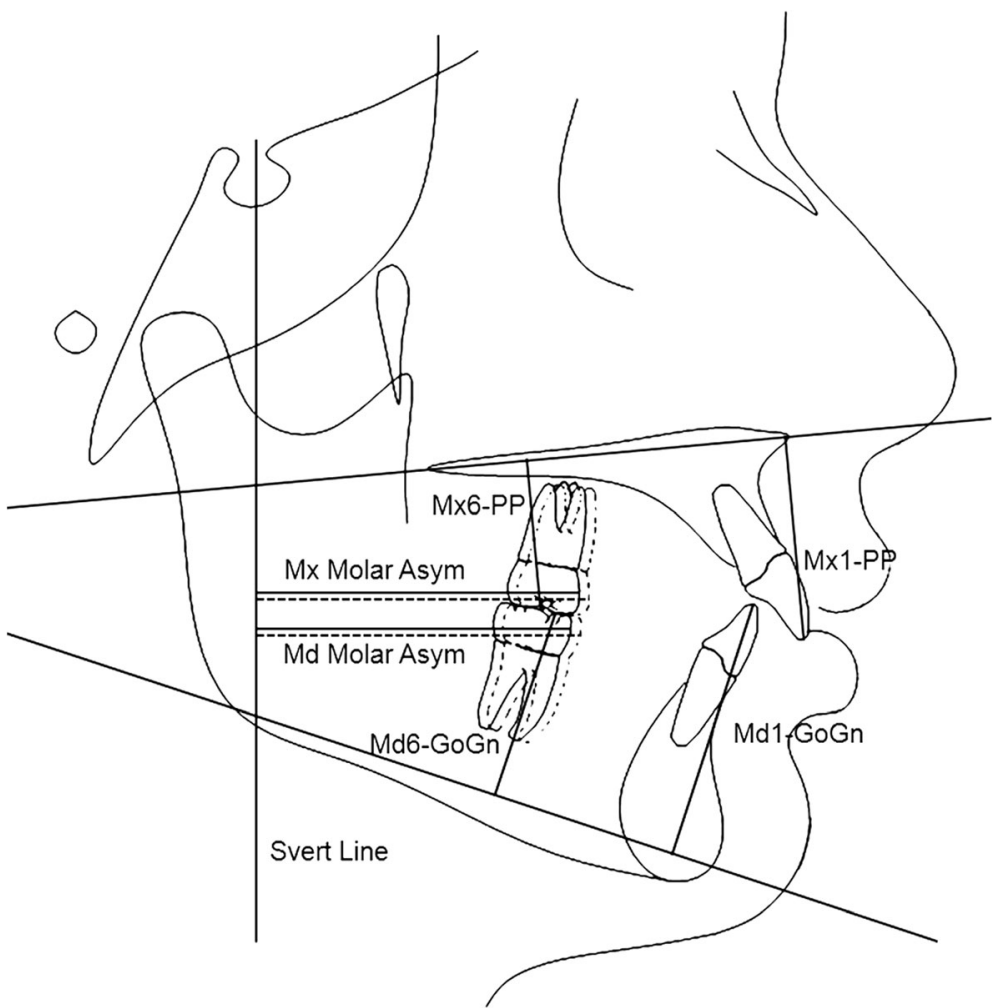

Fig. 3 Skeletal and dental variables. Angular measurements: SNA; SNB; ANB; NAP; SN.GoGn; Mx1.NA; Md1.NB; IMPA. Linear measurements: Co-A; Co-Gn; LAFH; Overbite, Overjet, Mx1-NA; Md1-NB; Mx1-PP; Mx6-PP; Md1-GoGn; Md6-GoGn; Mx Molar Asymmetry; Md Molar Asymmetry 


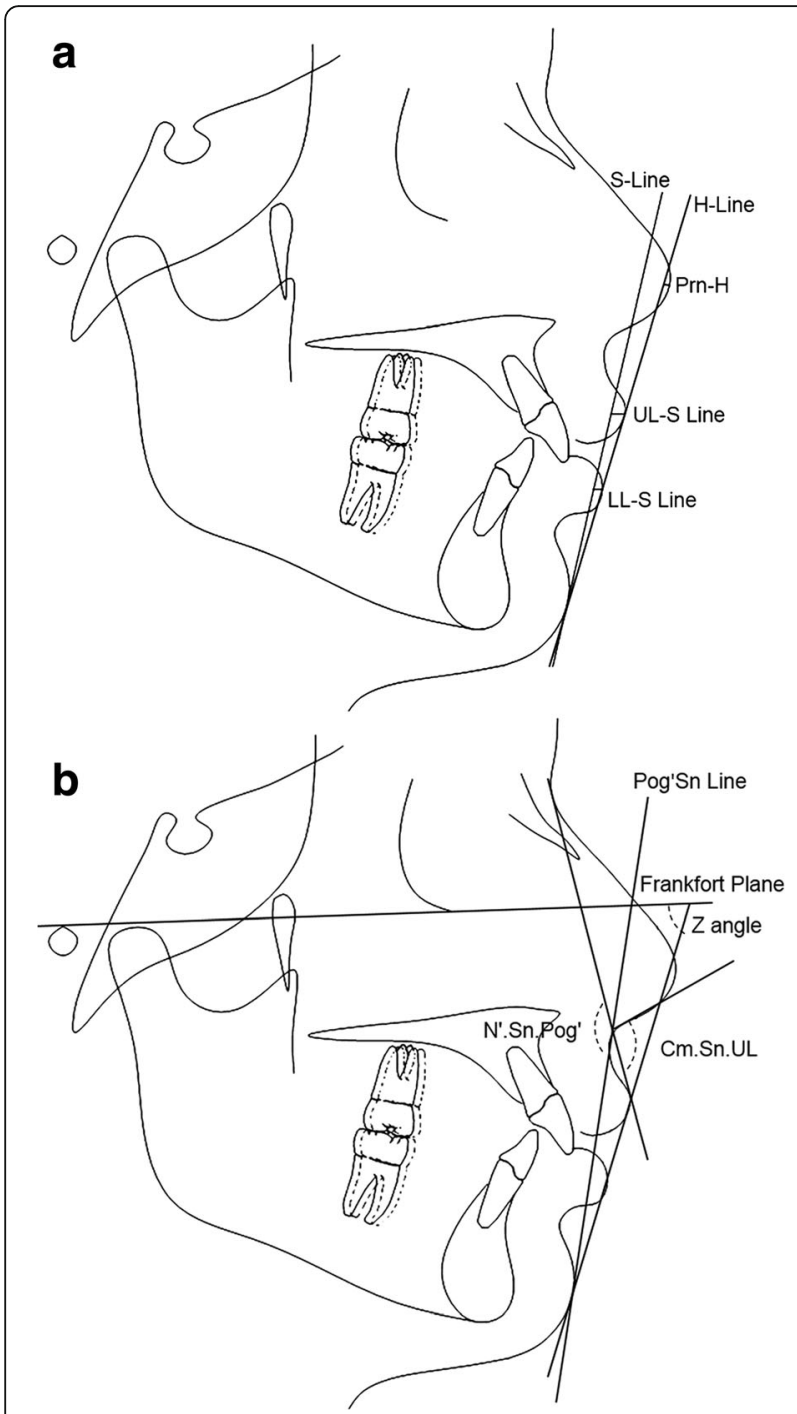

Fig. 4 Soft tissue variables. Linear measurements (a): UL-S Line; Prn-H; LL-S Line. Angular measurements (b): Z Angle; N'.Sn.Pog'; Cm.Sn.UL

the cephalometric software. Subsequently, 35 landmarks in the dentoskeletal facial structures and 17 landmarks in the soft tissue were marked (Figs. 3 and 4, Table 1).

For dental asymmetry assessment, two digital tracings were performed for each patient at $\mathrm{T} 1$ and $\mathrm{T} 2$. In the first tracing, linear measurements were made from the mesial point of the most mesial maxillary and mandibular molar, perpendicularly, to the Svert Line (6-Svert). In the second tracing, linear measurements were made from the mesial point of the most distal maxillary and mandibular molar, perpendicularly, to the same vertical reference line (6-Svert). Asymmetry was calculated as the difference between the most mesial and distal molars for the maxillary and mandibular molars [2, 9].

The Little irregularity index [16] was used to calculate crowding at the pretreatment stage. This index was originally used to evaluate anterior mandibular dental crowding, and has been adapted to also quantify maxillary anterior crowding [17].

\section{Error study}

Twenty-two lateral cephalograms were randomly selected and remeasured by the same examiner (EBL), after a 30-day interval. Random errors were calculated according to Dahlberg's formula $\left(\mathrm{Se}^{2}=\sum d^{2} / 2 n\right)$ [18], where $S^{2}$ is the error variance and $d$ is the difference between 2 determinations of the same variable and the systematic errors were evaluated with dependent $t$ tests, at $P<0.05$ [19].

\section{Statistical analyses}

The means and standard deviations (SD) for each variable were calculated for both groups. KolmogorovSmirnov tests were applied to verify normal distribution of the variables. The results of the tests were nonsignificant for all variables. Therefore, intergroup comparability was evaluated with $t$ tests regarding the initial and final ages, treatment time and the cephalometric characteristics at the pretreatment stage. Chisquare test was used to compare sex distribution in the groups.

$t$ tests were also used to compare the treatment changes and the cephalometric status at the posttreatment stage. All tests were performed with Statistica software (Version 7, StatSoft Inc., Tulsa, OK, USA), at $P<.05$.

\section{Results}

The random errors ranged from 0.44 (overbite) to $1.38 \mathrm{~mm}$ (CoGn) and from 0.77 (SND) to $1.45^{\circ}$ (Cm.Sn.Ls). Only two variables (LAFH and $\mathrm{Z}$ angle) presented significant systematic errors. The groups were comparable regarding the initial age, treatment time, sex distribution, and initial occlusal characteristics (Table 2). At the pretreatment stage, group 2 had significantly smaller maxillary incisor dentoalveolar development, greater maxillary molar asymmetry, smaller mandibular molar asymmetry, greater nasal prominence, and smaller lower lip protrusion (Table 3).

During treatment, there was significantly greater maxillomandibular relationship improvement, decrease in facial convexity, and increase in molar dentoalveolar height in group 1 (Table 4). Group 2 presented significantly greater increase in maxillary molar asymmetry. There was significant differences regarding mandibular incisor behavior. While group 2 had labial tipping 
Table 1 Skeletal, dental and soft tissue cephalometric variables

\begin{tabular}{ll}
\hline Maxillary skeletal components \\
SNA & SN to NA angle \\
Co-A & Condylion to A-point distance
\end{tabular}

Mandibular skeletal components

$\begin{array}{ll}\text { SNB } & \text { SN to NB angle } \\ \text { Co-Gn } & \text { Condylion to gnathion distance }\end{array}$

Maxillomandibular relationship

$\begin{array}{ll}\text { ANB } & \text { NA to NB angle } \\ \text { NAP } & \text { Angle between lines NA and AP } \\ \text { Growth pattern } & \\ \text { SN.GoGn } & \text { SN to GoGn angle } \\ \text { LAFH } & \begin{array}{l}\text { ANS, anterior nasal spine to menton } \\ \text { distance }\end{array}\end{array}$

Maxillary dentoalveolar components

$\begin{array}{ll}\text { Mx1.NA } & \text { Maxillary incisor long axis to NA angle } \\ \text { Mx1-NA } & \begin{array}{l}\text { Distance between most anterior point } \\ \text { crown of maxillary incisor and NA line }\end{array} \\ \text { Mx6-PP } & \begin{array}{l}\text { Perpendicular distance between the in } \\ \text { edge of the maxillary incisor and the } \\ \text { palatal plane }\end{array} \\ & \begin{array}{l}\text { Perpendicular distance between the } \\ \text { maxillary first molar mesial and distal } \\ \text { cusps midpoint and the palatal plane }\end{array} \\ & \begin{array}{l}\text { Difference in the distance between } \\ \text { most mesial points of right and left } \\ \text { maxillary first molars, perpendicular } \\ \text { to Svert Line (Mx6-Svert) }\end{array}\end{array}$

Mandibular dentoalveolar components

\begin{tabular}{|c|c|}
\hline Md1.NB & Mandibular incisor long axis to NB angle \\
\hline Md1-NB & $\begin{array}{l}\text { Distance between most anterior point of } \\
\text { crown of mandibular incisor and NB line }\end{array}$ \\
\hline IMPA & Incisor mandibular plane angle \\
\hline Md1-GoGn & $\begin{array}{l}\text { Perpendicular distance between the } \\
\text { incisal edge of the mandibular incisor } \\
\text { and the mandibular plane }\end{array}$ \\
\hline Md6-GoGn & $\begin{array}{l}\text { Perpendicular distance between the } \\
\text { mesiobuccal cusp tip of the mandibular } \\
\text { first molar and the mandibular plane }\end{array}$ \\
\hline Md Molar asymmetry & $\begin{array}{l}\text { Difference in the distance between } \\
\text { most mesial points of right and left } \\
\text { maxillary first molars, perpendicular } \\
\text { to Svert Line (Md6-Svert) }\end{array}$ \\
\hline
\end{tabular}

Dental relationship

Overjet Distance between incisal edges of maxillary and mandibular central incisors, parallel to occlusal plane

Overbite

Upper lip

UL-S line

Prn-H
Table 1 Skeletal, dental and soft tissue cephalometric variables (Continued)

Distance between $\mathrm{H}$ line and the most
anterior point on the nose

Lower lip

LL-S line Distance from the lower lip to

Steiner's S line

Facial convexity and nasolabial angle

$\mathrm{Z}$ angle

Angle formed by the intersection of Frankfort horizontal plane and a line connecting the soft-tissue chin ( $\left.\mathrm{Pg}^{\prime}\right)$ and the most protrusive lip point

N'Sn.Pog' Facial convexity

Cm.Sn.UL Nasolabial angle

and protrusion of the incisors, group 1 had lingual tipping and retrusion. Group 1 had greater increase in mandibular molar asymmetry.

At the posttreatment stage, group 1 demonstrated significantly greater LAFH, smaller labial tipping, and greater dentoalveolar height of the maxillary incisors (Table 5). Group 1 also presented greater maxillary molar dentoalveolar height and smaller maxillary molar asymmetry. Group 2 presented greater labial tipping and protrusion of the mandibular incisors, smaller mandibular molar asymmetry, and greater facial convexity.

\section{Discussion}

Groups' comparability

Only class II subdivision malocclusion patients, with complete class II on one side and class I on the other, independently of the associated cephalometric factors were included [7]. Group 1 had significantly greater maxillary incisor dentoalveolar height, smaller maxillary molar asymmetry, and greater mandibular molar asymmetry (Table 3). The greater maxillary incisor dentoalveolar height suggests a slightly more accentuated vertical growth pattern and the differences in molar asymmetry are characteristics of the two types of subdivision malocclusions [4-6, 11, 20]. Group 1 had also greater lower lip protrusion which might also have contributed for the extraction treatment in this group. However, these slight differences should not interfere with the comparison.

\section{Treatment changes and posttreatment status}

The greater reduction in maxillomandibular relationship in group 1 may be consequent to the greater number of extractions in the maxillary arch, and increased need for class II elastics or headgear, to reinforce anchorage, that consequently produced a non-significantly 
Table 2 Intergroup baseline comparability ( $t$ and Chi-square tests)

\begin{tabular}{|c|c|c|c|c|c|}
\hline \multirow[b]{2}{*}{ Variables } & \multicolumn{2}{|c|}{ Group 1-3 extractions $(n=31)$} & \multicolumn{2}{|c|}{ Group 2-1 extraction $(n=32)$} & \multirow[b]{2}{*}{$P$} \\
\hline & Mean & S.D. & Mean & S.D. & \\
\hline Initial age & 13.58 & 2.26 & 13.98 & 1.66 & $0.425^{\mathrm{a}}$ \\
\hline Final age & 16.83 & 2.39 & 16.90 & 1.85 & $0.888^{\mathrm{a}}$ \\
\hline Treatment time & 3.25 & 1.02 & 2.92 & 1.02 & $0.210^{\mathrm{a}}$ \\
\hline \multicolumn{6}{|l|}{ Sex } \\
\hline Male & 13 & & 12 & & \\
\hline Female & 18 & & 20 & & $0.719^{b}$ \\
\hline $\begin{array}{l}\text { Maxillary Little } \\
\text { Irregularity Index }\end{array}$ & 5.33 & 4.02 & 4.22 & 2.74 & $0.202^{\mathrm{a}}$ \\
\hline $\begin{array}{l}\text { Mandibular Little } \\
\text { Irregularity Index }\end{array}$ & 2.52 & 1.52 & 2.43 & 1.74 & $0.824^{\mathrm{a}}$ \\
\hline
\end{tabular}

greater maxillary retraction [21-23], Table 4. Group 1 also had a non-significantly greater increase in mandibular growth. These non-significant greater changes in group 1, when associated, might have contributed for a significantly greater reduction in maxillomandibular relationship than group 2. Additionally, these associated greater non-significant changes might have also contributed for a greater reduction in skeletal facial convexity in group 1 . However, these greater treatment changes of group 1 were not enough to produce intergroup differences at the posttreatment stage (Table 5).

Despite there were no significant intergroup differences in maxillary incisor treatment changes, they were significantly more palatally tipped and had greater dentoalveolar height in group 1, at the posttreatment stage (Tables 4 and 5). The greater palatal inclination was probably consequent to the non-significant greater palatal tipping that occurred during treatment in this group because of incisor retraction to close the two maxillary premolar extraction spaces. Group 1 already had greater dentoalveolar height at the pretreatment stage and because the vertical treatment changes were similar in the groups, the initial intergroup pretreatment difference was maintained.

The greater increase in molar dentoalveolar height in group 1 was probably due to greater need of intermaxillary elastics and/or headgear use, associated with the slightly greater vertical growth pattern of this group [7, 9, 24], Table 4 . The three premolar extraction protocol performed in group 1 requires greater amount of anchorage reinforcement during anterior retraction, compared to the one premolar extraction protocol performed in group 2. Therefore, this may have contributed to more extrusion in group 1 . Consequently to this, LAFH and maxillary molar dentoalveolar height were significantly greater in group 1 , at the posttreatment stage, which usually occurs $[9,24]$, Table 5.

Because group 2 had only one maxillary premolar extraction, it is quite obvious that maxillary molar asymmetry had greater increase in this group than in group 1 , which increased even more the significant initial intergroup difference in molar asymmetry (Tables 4 and 5). Nevertheless, this amount of asymmetry between the maxillary molars in group 2 is not clinically relevant and does not bring any decrease in smile attractiveness $[13,25,26]$.

The significant intergroup differences in mandibular incisor behavior was consequent to the non-extraction treatment in group 2 and one premolar extraction treatment in group 1 (Table 4). Therefore, there was mandibular incisor labial inclination and protrusion resulting from correction of the anterior crowding and leveling of the curve of Spee without mandibular premolar extraction in group $2[11,27,28]$. In group 1 , there was retraction and lingual inclination of the mandibular incisors as a result of space closure of one mandibular premolar extraction [13, 29]. Consequent to these different changes, the mandibular incisors of group 1 were significantly more lingually tipped and retruded than those of group 2 at the posttreatment stage (Table 5).

Similarly to the maxillary molars because group 1 had only one mandibular premolar extraction, it is quite obvious that mandibular molar asymmetry had greater increase in this group than in group 2, which increased even more the significant initial intergroup difference in molar asymmetry, at the posttreatment stage (Tables 4 and 5 ).

Group 1 presented a significantly smaller facial convexity at the posttreatment stage, probably because of 
Table 3 Intergroup comparison at the pretreatment stage ( $t$ tests)

\begin{tabular}{|c|c|c|c|c|c|}
\hline \multirow[b]{2}{*}{ Variables } & \multicolumn{2}{|c|}{ Group 1-3 extractions $(n=31)$} & \multicolumn{2}{|c|}{ Group 2-1 extraction $(n=32)$} & \multirow[b]{2}{*}{$P$} \\
\hline & Mean & S.D. & Mean & S.D. & \\
\hline \multicolumn{6}{|l|}{ Maxillary component } \\
\hline SNA $\left(^{\circ}\right)$ & 84.10 & 4.10 & 83.28 & 4.04 & 0.429 \\
\hline Co-A (mm) & 82.65 & 3.81 & 83.41 & 3.53 & 0.415 \\
\hline \multicolumn{6}{|l|}{ Mandibular component } \\
\hline SNB $\left(^{\circ}\right)$ & 79.32 & 3.98 & 79.26 & 3.06 & 0.946 \\
\hline Co-Gn (mm) & 110.95 & 4.59 & 111.96 & 5.89 & 0.451 \\
\hline \multicolumn{6}{|l|}{ Maxillomandibular relationship } \\
\hline ANB $\left(^{\circ}\right)$ & 4.77 & 1.75 & 4.02 & 2.19 & 0.137 \\
\hline $\operatorname{NAP}\left({ }^{\circ}\right)$ & 171.65 & 4.39 & 172.88 & 4.11 & 0.254 \\
\hline \multicolumn{6}{|l|}{ Growth pattern } \\
\hline SN.GoGn $\left(^{\circ}\right)$ & 29.19 & 3.96 & 27.86 & 4.36 & 0.210 \\
\hline LAFH (mm) & 63.43 & 4.33 & 62.32 & 4.41 & 0.316 \\
\hline \multicolumn{6}{|c|}{ Maxillary dentoalveolar component } \\
\hline $\mathrm{M} \times 1 . \mathrm{NA}\left({ }^{\circ}\right)$ & 24.45 & 5.49 & 25.75 & 7.16 & 0.423 \\
\hline $\mathrm{M} \times 1-\mathrm{NA}(\mathrm{mm})$ & 5.53 & 2.44 & 5.50 & 3.86 & 0.971 \\
\hline $\mathrm{M} \times 1-\mathrm{PP}(\mathrm{mm})$ & 28.40 & 2.23 & 26.81 & 2.95 & $0.018^{\mathrm{a}}$ \\
\hline M×6-PP (mm) & 20.35 & 2.36 & 19.43 & 1.98 & 0.098 \\
\hline Mx Molar asymmetry (mm) & 1.99 & 0.33 & 2.19 & 0.39 & $0.025^{\mathrm{a}}$ \\
\hline \multicolumn{6}{|c|}{ Mandibular dentoalveolar component } \\
\hline $\operatorname{Md} 1 . N B\left({ }^{\circ}\right)$ & 28.82 & 5.01 & 27.85 & 6.02 & 0.489 \\
\hline Md1-NB (mm) & 5.87 & 1.41 & 5.94 & 2.10 & 0.872 \\
\hline $\operatorname{IMPA}\left({ }^{\circ}\right)$ & 97.56 & 5.83 & 99.22 & 7.93 & 0.350 \\
\hline Md1-GoGn (mm) & 35.97 & 2.29 & 35.46 & 2.86 & 0.442 \\
\hline Md6-GoGn (mm) & 26.83 & 2.19 & 27.32 & 2.33 & 0.387 \\
\hline Md Molar asymmetry (mm) & 2.09 & 0.46 & 1.79 & 0.57 & $0.025^{\mathrm{a}}$ \\
\hline \multicolumn{6}{|l|}{ Dental relationship } \\
\hline Overjet (mm) & 4.88 & 1.80 & 4.96 & 1.78 & 0.856 \\
\hline Overbite (mm) & 1.89 & 2.31 & 1.97 & 1.10 & 0.863 \\
\hline \multicolumn{6}{|l|}{ Upper lip } \\
\hline UL-S line $(\mathrm{mm})$ & 2.41 & 2.42 & 1.41 & 1.98 & 0.077 \\
\hline Prn-H (mm) & 0.91 & 4.56 & 3.31 & 4.00 & $0.030^{\mathrm{a}}$ \\
\hline \multicolumn{6}{|l|}{ Lower lip } \\
\hline LL-S line (mm) & 3.50 & 3.04 & 1.95 & 2.46 & $0.029^{\mathrm{a}}$ \\
\hline \multicolumn{6}{|c|}{ Facial convexity and nasolabial angle } \\
\hline Z Angle $\left(^{\circ}\right)$ & 75.85 & 5.51 & 73.92 & 6.61 & 0.214 \\
\hline$N^{\prime} . S_{n} \cdot \operatorname{Pog}^{\prime}\left({ }^{\circ}\right)$ & 156.08 & 5.13 & 157.63 & 6.07 & 0.276 \\
\hline Cm.Sn.UL $\left(^{\circ}\right)$ & 105.07 & 8.93 & 101.23 & 8.26 & 0.081 \\
\hline
\end{tabular}

${ }^{\text {a Statistically significant at } P<0.05}$

the non-significanly greater upper lip retrusion, with treatment, than group 2 [21, 29-32].

The two treatment protocols for class II subdivision malocclusions produced significantly different changes in certain dentoalveolar variables. This is reasonable because each of these protocols are indicated for different types of class II subdivision malocclusions. For type 1, three premolar extractions are indicated 
Table 4 Intergroup comparison of treatment changes ( $t$ tests)

\begin{tabular}{|c|c|c|c|c|c|}
\hline \multirow[b]{2}{*}{ Variables } & \multicolumn{2}{|c|}{ Group 1-3 extractions $(n=31)$} & \multicolumn{2}{|c|}{ Group 2-1 extraction $(n=32)$} & \multirow[b]{2}{*}{$P$} \\
\hline & Mean & S.D. & Mean & S.D. & \\
\hline \multicolumn{6}{|l|}{ Maxillary component } \\
\hline SNA $\left({ }^{\circ}\right)$ & -1.73 & 3.17 & -0.58 & 2.79 & 0.131 \\
\hline Co-A (mm) & -0.95 & 4.12 & -0.29 & 2.00 & 0.416 \\
\hline \multicolumn{6}{|l|}{ Mandibular component } \\
\hline SNB $\left(^{\circ}\right)$ & 0.49 & 2.27 & -0.02 & 2.27 & 0.376 \\
\hline Co-Gn (mm) & 3.55 & 5.14 & 1.98 & 3.27 & 0.153 \\
\hline \multicolumn{6}{|l|}{ Maxillomandibular relationship } \\
\hline ANB $\left(^{\circ}\right)$ & -2.21 & 2.19 & -0.56 & 1.87 & $0.002^{\mathrm{a}}$ \\
\hline $\operatorname{NAP}\left({ }^{\circ}\right)$ & 2.95 & 4.44 & 0.49 & 2.79 & $0.010^{\mathrm{a}}$ \\
\hline \multicolumn{6}{|l|}{ Growth pattern } \\
\hline SN.GoGn $\left(^{\circ}\right)$ & -0.58 & 2.89 & -1.18 & 3.12 & 0.434 \\
\hline LAFH (mm) & 2.45 & 2.56 & 1.10 & 3.51 & 0.088 \\
\hline \multicolumn{6}{|c|}{ Maxillary dentoalveolar component } \\
\hline $\mathrm{M} \times 1 . \mathrm{NA}\left({ }^{\circ}\right)$ & -1.11 & 6.38 & 1.91 & 7.80 & 0.098 \\
\hline $\mathrm{M} \times 1-\mathrm{NA}(\mathrm{mm})$ & -0.68 & 3.09 & -0.38 & 3.27 & 0.716 \\
\hline $\mathrm{M} \times 1-\mathrm{PP}(\mathrm{mm})$ & -0.66 & 1.24 & -0.43 & 1.74 & 0.533 \\
\hline $\mathrm{M} \times 6-\mathrm{PP}(\mathrm{mm})$ & 1.96 & 2.10 & 0.78 & 1.98 & $0.024^{\mathrm{a}}$ \\
\hline Mx Molar asymmetry (mm) & -0.16 & 0.43 & 0.75 & 1.13 & $0.000^{\mathrm{a}}$ \\
\hline \multicolumn{6}{|c|}{ Mandibular dentoalveolar component } \\
\hline Md1.NB $\left(^{\circ}\right)$ & -1.03 & 5.08 & 3.09 & 4.59 & $0.001^{\mathrm{a}}$ \\
\hline Md1-NB (mm) & -0.47 & 0.96 & 0.86 & 1.34 & $0.000^{\mathrm{a}}$ \\
\hline $\operatorname{IMPA}\left({ }^{\circ}\right)$ & -0.67 & 5.58 & 3.13 & 5.62 & $0.009^{\mathrm{a}}$ \\
\hline Md1-GoGn (mm) & 0.98 & 2.05 & 0.49 & 1.86 & 0.325 \\
\hline Md6-GoGn (mm) & 2.12 & 1.67 & 1.40 & 1.63 & 0.087 \\
\hline Md Molar asymmetry (mm) & 1.06 & 0.57 & 0.09 & 0.72 & $0.000^{\mathrm{a}}$ \\
\hline \multicolumn{6}{|l|}{ Dental relationship } \\
\hline Overjet (mm) & -2.23 & 1.72 & -2.03 & 1.87 & 0.648 \\
\hline Overbite (mm) & -0.88 & 2.27 & -1.16 & 1.31 & 0.551 \\
\hline \multicolumn{6}{|l|}{ Upper lip } \\
\hline UL-S Line (mm) & -1.85 & 2.34 & -1.28 & 1.44 & 0.241 \\
\hline Prn-H (mm) & 3.80 & 4.43 & 2.65 & 2.88 & 0.223 \\
\hline \multicolumn{6}{|l|}{ Lower lip } \\
\hline LL-S Line (mm) & -1.68 & 2.27 & -0.88 & 1.47 & 0.101 \\
\hline \multicolumn{6}{|c|}{ Facial convexity and nasolabial angle } \\
\hline Z Angle $\left(^{\circ}\right)$ & 2.15 & 4.72 & 0.68 & 5.41 & 0.254 \\
\hline$N^{\prime} . S n \cdot P_{0 g}\left({ }^{\circ}\right)$ & 1.41 & 4.68 & 0.03 & 3.89 & 0.207 \\
\hline Cm.Sn.UL $\left(^{\circ}\right)$ & 1.71 & 7.73 & 1.69 & 9.22 & 0.992 \\
\hline
\end{tabular}

${ }^{\text {a Statistically significant at } P<0.05}$

$[1,6-9,11-13]$. This is the case when maxillary incisor protrusion or crowding is accentuated and there is also some mandibular crowding or incisor protrusion $[7,9,11,12,33]$. Therefore, this protocol will solve these problems $[8,13,24]$. For type 2, there is usually less maxillary incisor protrusion and there is no mandibular crowding, with the incisors labiolingually well positioned. Therefore, the treatment changes will be favorable according to each malocclusion need. 
Table 5 Intergroup comparison at the posttreatment stage ( $t$ tests)

\begin{tabular}{|c|c|c|c|c|c|}
\hline \multirow[b]{2}{*}{ Variables } & \multicolumn{2}{|c|}{ Group 1-3 extractions $(n=31)$} & \multicolumn{2}{|c|}{ Group 2-1 extraction $(n=32)$} & \multirow[b]{2}{*}{$P$} \\
\hline & Mean & S.D. & Mean & S.D. & \\
\hline \multicolumn{6}{|l|}{ Maxillary component } \\
\hline SNA $\left(^{\circ}\right)$ & 82.37 & 4.75 & 82.70 & 4.65 & 0.778 \\
\hline Co-A (mm) & 81.77 & 4.00 & 83.12 & 3.46 & 0.156 \\
\hline \multicolumn{6}{|l|}{ Mandibular component } \\
\hline SNB $\left(^{\circ}\right)$ & 79.81 & 4.22 & 79.24 & 2.55 & 0.518 \\
\hline Co-Gn (mm) & 114.50 & 6.30 & 113.95 & 5.36 & 0.708 \\
\hline \multicolumn{6}{|l|}{ Maxillomandibular relationship } \\
\hline ANB $\left(^{\circ}\right)$ & 2.56 & 2.44 & 3.46 & 2.83 & 0.183 \\
\hline $\operatorname{NAP}\left({ }^{\circ}\right)$ & 174.60 & 3.95 & 173.38 & 3.86 & 0.218 \\
\hline \multicolumn{6}{|l|}{ Growth pattern } \\
\hline SN.GoGn $\left(^{\circ}\right)$ & 28.61 & 5.45 & 26.68 & 4.80 & 0.140 \\
\hline LAFH (mm) & 65.88 & 4.76 & 63.42 & 4.77 & $0.044^{a}$ \\
\hline \multicolumn{6}{|c|}{ Maxillary dentoalveolar component } \\
\hline Mx1.NA $\left(^{\circ}\right)$ & 23.34 & 5.21 & 27.66 & 8.11 & $0.014^{a}$ \\
\hline $\mathrm{M} \times 1-\mathrm{NA}(\mathrm{mm})$ & 4.85 & 2.42 & 5.12 & 4.13 & 0.758 \\
\hline$M \times 1-P P(m m)$ & 27.74 & 2.27 & 26.38 & 2.81 & $0.039^{a}$ \\
\hline Mx6-PP (mm) & 22.31 & 2.21 & 20.20 & 2.19 & $0.000^{\mathrm{a}}$ \\
\hline Mx Molar asymmetry (mm) & 1.83 & 0.42 & 2.94 & 1.07 & $0.000^{\mathrm{a}}$ \\
\hline \multicolumn{6}{|c|}{ Mandibular dentoalveolar component } \\
\hline $\operatorname{Md} 1 . N B\left({ }^{\circ}\right)$ & 27.79 & 5.18 & 30.94 & 5.13 & $0.018^{a}$ \\
\hline Md1-NB (mm) & 5.42 & 1.39 & 6.80 & 2.00 & $0.002^{\mathrm{a}}$ \\
\hline $\operatorname{IMPA}\left({ }^{\circ}\right)$ & 96.89 & 6.49 & 102.34 & 7.39 & $0.002^{\mathrm{a}}$ \\
\hline Md1-GoGn (mm) & 36.95 & 2.94 & 35.95 & 2.89 & 0.180 \\
\hline Md6-GoGn (mm) & 28.95 & 2.28 & 28.72 & 2.58 & 0.713 \\
\hline Md Molar asymmetry (mm) & 3.15 & 0.58 & 1.88 & 0.54 & $0.000^{\mathrm{a}}$ \\
\hline \multicolumn{6}{|l|}{ Dental relationship } \\
\hline Overjet (mm) & 2.65 & 0.68 & 2.94 & 0.73 & 0.109 \\
\hline Overbite (mm) & 1.01 & 0.74 & 0.81 & 0.95 & 0.353 \\
\hline \multicolumn{6}{|l|}{ Upper lip } \\
\hline UL-S Line (mm) & 0.56 & 2.67 & 0.14 & 2.55 & 0.524 \\
\hline Prn-H (mm) & 4.72 & 5.07 & 5.96 & 4.64 & 0.312 \\
\hline \multicolumn{6}{|l|}{ Lower lip } \\
\hline LL-S Line (mm) & 1.81 & 2.86 & 1.07 & 2.48 & 0.272 \\
\hline \multicolumn{6}{|c|}{ Facial convexity and nasolabial angle } \\
\hline Z Angle $\left(^{\circ}\right)$ & 77.99 & 6.95 & 74.59 & 4.46 & $0.023^{\mathrm{a}}$ \\
\hline N'Sn.Pog $^{\prime}\left({ }^{\circ}\right)$ & 157.49 & 5.94 & 157.67 & 5.90 & 0.905 \\
\hline Cm.Sn.UL $\left(^{\circ}\right)$ & 106.79 & 9.51 & 102.93 & 10.55 & 0.132 \\
\hline
\end{tabular}

${ }^{\text {a Statistically significant at } P<0.05}$

\section{Conclusions}

The null hypothesis was rejected because the treatment changes had the following differences:

1. There was greater maxillomandibular sagittal discrepancy reduction in group 1 ;
2. There was greater maxillary first molar extrusion in group 1;

3. Maxillary molars asymmetry increased in group 2 and decreased in group 1.

4. There was greater mandibular incisor labial inclination and protrusion in group 2, and 
mandibular incisor lingual inclination and retrusion in group 1;

5. There was greater increase of mandibular molar asymmetry in group 1 .

\section{Acknowledgements}

The authors would like to thank São Paulo Research Foundation-FAPESP (Process Number 09/15135-3) for their financial support.

\section{Authors' contributions}

GJ contributed in the study conception, research supervision, and scientific and English revision. EBL contributed to the data collection, statistical analyses, and project development. RF and AADC contributed to data checking and manuscript drafting. DG contributed to scientific and English revision. MAL contributed to scientific revision. All authors read and approved the final manuscript.

\section{Ethics approval and consent to participate}

This study was approved by the Ethics in Research Committee of Bauru Dental School, University of São Paulo, Brazil.

\section{Consent for publication}

Written informed consent was obtained from the patients for publication of this research and accompanying images.

\section{Competing interests}

The authors declare that they have no competing interests.

\section{Publisher's Note}

Springer Nature remains neutral with regard to jurisdictional claims in published maps and institutional affiliations.

\section{Author details}

1Department of Orthodontics, Bauru Dental School, University of São Paulo, Alameda Octávio Pinheiro Brisolla 9-75, Bauru 17012-901, Brazil. ²Department of Orthodontics, Dental School, Federal University of Goiás, Goiania, Brazil.

Received: 19 July 2017 Accepted: 29 September 2017

Published online: 04 December 2017

\section{References}

1. Wertz RA. Diagnosis and treatment planning of unilateral class ॥ malocclusions. Angle Orthod. 1975;45:85-94.

2. Alavi DG, BeGole EA, Schneider BJ. Facial and dental arch asymmetries in class II subdivision malocclusion. Am J Orthod Dentofac Orthop. 1988:93:38-46.

3. Rose JM, Sadowsky C, BeGole EA, Moles R. Mandibular skeletal and dental asymmetry in class II subdivision malocclusions. Am J Orthod Dentofac Orthop. 1994;105:489-95.

4. Janson GR, Metaxas A, Woodside DG, de Freitas MR, Pinzan A. Threedimensional evaluation of skeletal and dental asymmetries in class II subdivision malocclusions. Am J Orthod Dentofac Orthop. 2001;119:406-18.

5. Janson G, de Lima KJ, Woodside DG, Metaxas A, de Freitas MR, Henriques JF. Class II subdivision malocclusion types and evaluation of their asymmetries. Am J Orthod Dentofac Orthop. 2007;131:57-66.

6. Rebellato J. Asymmetric extractions used in the treatment of patients with asymmetries. Semin Orthod. 1998:4:180-8.

7. Janson G, Dainesi EA, Henriques JF, de Freitas MR, de Lima KJ. Class II subdivision treatment success rate with symmetric and asymmetric extraction protocols. Am J Orthod Dentofac Orthop. 2003;124:257-64. quiz 339

8. Turpin DL. Correcting the class II subdivision malocclusion. Am J Orthod Dentofac Orthop. 2005;128:555-6.

9. Janson G, Carvalho PE, Cancado RH, de Freitas MR, Henriques JF. Cephalometric evaluation of symmetric and asymmetric extraction treatment for patients with class II subdivision malocclusions. Am J Orthod Dentofac Orthop. 2007;132:28-35

10. Janson G, Araki J, Estelita S, Camardella LT. Stability of class II subdivision malocclusion treatment with 3 and 4 premolar extractions. Prog Orthod. 2014;15:67.
11. Cassidy SE, Jackson SR, Turpin DL, Ramsay DS, Spiekerman C, Huang GJ. Classification and treatment of class II subdivision malocclusions. Am J Orthod Dentofac Orthop. 2014;145:443-51.

12. Janson G, Baldo T, Garib D, Barros SE, Silva Poletto R, Bittencourt Dos Santos P. Efficiency of class II subdivision malocclusion treatment with 3 and 4 premolar extractions. Am J Orthod Dentofac Orthop. 2016;150:499-503.

13. Janson G, Woodside DG, Metaxas A, Henriques JF, Freitas MR. Orthodontic treatment of subdivision cases. World J Orthod. 2003;4:36-46.

14. Dahiya G, Masoud Al, Viana G, Obrez A, Kusnoto B, Evans CA. Effects of unilateral premolar extraction treatment on the dental arch forms of class $\|$ subdivision malocclusions. Am J Orthod Dentofac Orthop. 2017:152:232-41.

15. Ferro F, Monsurro A, Perillo L. Sagittal and vertical changes after treatment of class II division 1 malocclusion according to the Cetlin method. Am J Orthod Dentofac Orthop. 2000;118:150-8.

16. Little RM. The irregularity index: a quantitative score of mandibular anterior alignment. Am J Orthod. 1975;68:554-63.

17. Bernabé E, Flores-Mir C. Estimating arch length discrepancy through Little's Irregularity Index for epidemiological use. Eur J Orthod. 2006;28:269-73.

18. Dahlberg G. Statistical methods for medical and biological students. New York: Interscience Publications; 1940.

19. Houston WJ. The analysis of errors in orthodontic measurements. Am J Orthod. 1983:83:382-90

20. Minich CM, Araujo EA, Behrents RG, Buschang PH, Tanaka OM, Kim KB. Evaluation of skeletal and dental asymmetries in Angle class II subdivision malocclusions with cone-beam computed tomography. Am J Orthod Dentofac Orthop. 2013:144:57-66.

21. Scott Conley R, Jernigan C. Soft tissue changes after upper premolar extraction in class II camouflage therapy. Angle Orthod. 2006;76:59-65.

22. Sharma JN. Skeletal and soft tissue point A and B changes following orthodontic treatment of Nepalese class I bimaxillary protrusive patients. Angle Orthod. 2010;80:91-6.

23. Janson G, Aliaga-Del Castillo A, Niederberger A. Changes in apical base sagittal relationship in class II malocclusion treatment with and without premolar extractions: a systematic review and meta-analysis. Angle Orthod. 2017;87:338-55.

24. Burstone CJ. Diagnosis and treatment planning of patients with asymmetries. Semin Orthod. 1998:4:153-64.

25. Sanders DA, Rigali PH, Neace WP, Uribe F, Nanda R. Skeletal and dental asymmetries in class II subdivision malocclusions using cone-beam computed tomography. Am J Orthod Dentofac Orthop. 2010;138:542.e1-20.

26. Janson G, Branco NC, Morais JF, Freitas MR. Smile attractiveness in patients with class II division 1 subdivision malocclusions treated with different tooth extraction protocols. Eur J Orthod. 2014;36:1-8.

27. Bernstein RL, Preston CB, Lampasso J. Leveling the curve of Spee with a continuous archwire technique: a long term cephalometric study. Am J Orthod Dentofac Orthop. 2007:131:363-71.

28. Millett DT, Cunningham SJ, O'Brien KD, Benson PE, de Oliveira CM. Treatment and stability of class II division 2 malocclusion in children and adolescents: a systematic review. Am J Orthod Dentofac Orthop. 2012;142:159-69. e9

29. Bishara SE, Cummins DM, Jakobsen JR, Zaher AR. Dentofacial and soft tissue changes in class II, division 1 cases treated with and without extractions. Am J Orthod Dentofac Orthop. 1995;107:28-37.

30. Talass MF, Talass L, Baker RC. Soft-tissue profile changes resulting from retraction of maxillary incisors. Am J Orthod Dentofac Orthop. 1987;91:385-94.

31. Verma SL, Sharma VP, Singh GP, Sachan K. Comparative assessment of soft-tissue changes in class II division 1 patients following extraction and non-extraction treatment. Dent Res J. 2013;10:764-71.

32. Maetevorakul S, Viteporn S. Factors influencing soft tissue profile changes following orthodontic treatment in patients with class II division 1 malocclusion. Prog Orthod. 2016;17:13.

33. Guo Y, $\operatorname{Han} X, X u H, A i D$, Zeng H, Bai D. Morphological characteristics influencing the orthodontic extraction strategies for Angle's class II division 1 malocclusions. Prog Orthod. 2014;15:44-50. 